\title{
Inhibition of the leptin-induced activation of the p38 MAPK pathway contributes to the protective effects of naringin against high glucose-induced injury in $\mathrm{H9c2}$ cardiac cells
}

\author{
JINGFU CHEN*, HAILIANG MO, RUNMIN GUO, QIONG YOU, RUINA HUANG and KENG WU* \\ Department of Cardiovasology, The Affiliated Hospital, Guangdong Medical College, \\ Zhanjiang, Guangdong 524001, P.R. China
}

Received September 4, 2013; Accepted December 24, 2013

DOI: $10.3892 / \mathrm{ijmm} .2014 .1614$

\begin{abstract}
Leptin, a product of the obese gene, has been reported to contribute to the development of cardiomyocyte hypertrophy in patients with diabetes and to activate the p38 mitogen-activated protein kinase (MAPK) pathway in cardiomyocytes. In this study, we demonstrate that naringin, a citrus flavonone, protects cardiomyoblasts (H9c2 cells) against high glucose (HG)-induced apoptosis by modulating the activation of the p38 MAPK pathway. We investigated the hypothesis that naringin prevents HG-induced injury by inhibiting the leptin-induced activation of the p38 MAPK pathway in H9c2 cells. Our results demonstrated that the exposure of $\mathrm{H} 9 \mathrm{c} 2$ cells to $\mathrm{HG}(35 \mathrm{mmol} / \mathrm{l})$ for a $24 \mathrm{~h}$ markedly upregulated the expression levels of both leptin and leptin receptors. However, the increase in the expression levels of leptin and leptin receptors was greatly attenuated by treatment of the H9c2 cells with $80 \mu \mathrm{mol} / \mathrm{l}$ naringin $2 \mathrm{~h}$ prior to exposure to $\mathrm{HG}$. In addition, treatment of the cells with $50 \mathrm{ng} / \mathrm{ml}$ leptin antagonist (LA) for $24 \mathrm{~h}$ prior to exposure to $\mathrm{HG}$ markedly ameliorated the increased expression of phosphorylated (p)-p38 MAPK induced by HG. Of note, pre-treatment of the cells with either $80 \mu \mathrm{mol} / 1$ naringin or $50 \mathrm{ng} / \mathrm{ml} \mathrm{LA} \mathrm{markedly} \mathrm{inhibited} \mathrm{the} \mathrm{HG-induced}$ injury, leading to an increase in cell viability and a decrease in the total number of apoptotic cells, preventing reactive oxygen species (ROS) generation, as well as the dissipation of mitochondrial membrane potential (MMP). In conclusion, the findings of the present study provide the first evidence that the leptin-induced activation of the p38 MAPK pathway is involved in HG-induced injury, including cytotoxicity, apoptosis, ROS
\end{abstract}

Correspondence to: Dr Keng Wu, Department of Cardiovasology, The Affiliated Hospital, Guangdong Medical College, 57 Renmin Avenue South, Zhanjiang, Guangdong 524001, P.R. China

E-mail: wukeng1245@hotmail.com

${ }^{*}$ Contributed equally

Key words: naringin, high glucose, H9c2 cells, leptin, p38 mitogenactivated protein kinase generation and the dissipation of MMP in H9c2 cardiac cells. Our data demonstrate that naringin protects cardiac cells against HG-induced injury by inhibiting the leptin-induced activation of the p38 MAPK pathway.

\section{Introduction}

Naringin (4',5,7-trihydroxyflavonone-7-rhamnoglucoside), is a flavonone found in citrus fruit, such as grapefruit. Accumulating evidence has indicated that naringin has a broad spectrum of pharmacological and therapeutic properties, including antioxidant (1-5), antihypercholesterolemic (5-7), anti-inflammatory $(1,4,5,8)$ and anti-apoptotic effects (9-12). Notably, naringin has antihyperglycemic properties $(13,14)$ and cardioprotective effects $(12,15,16)$. A recent study demonstrated that naringin protects $\mathrm{H} 9 \mathrm{c} 2$ cardiac cells against high glucose (HG)-induced apoptosis by inhibiting the activation of the p38 mitogen-activated protein kinase (MAPK) pathway (12). Accordingly, we hypothesized that the molecules which activate the p38 MAPK pathway may contribute to HG-induced cardiomyocyte injury and to the cardioprotective effects of naringin. Thus, in this study, we investigated one ot these molecules, leptin.

Leptin, a 16-kDa peptide released from adipocytes and other cells, has been implicated in the regulation of appetite and energy metabolism $(17,18)$. Leptin was initially thought to mainly regulate obesity or body weight. However, increasing evidence has demonstrated the effects of leptin in the regulation of inflammation (19), blood pressure homeostasis and cardiovascular disease (20-23). Leptin receptors have a widespread tissue distribution, including the kidneys, pancreas, lungs and heart $(22,24-26)$, through which leptin exerts its physiological effects, primarily by activating Janus tyrosine kinase (JAK), signal transducers and signal transducers and activators of transcription (STATs) (27). In addition, previous studies have demonstrated that leptin can also activate other signaling cascades, such as extracellular signal-regulated kinase 1/2 (ERK1/2) (28), c-Jun N-terminal kinase/stressactivated protein kinase (JNK) (29) and p38 MAPK (30-33) of the MAPK family in a variety of cell types. A previous study demonstrated that leptin induces the selective translocation of p38 MAPK from the cytoplasmic to the nuclear fraction and is 
dependent on intact caveolae and on the activity of the RhoA pathway (33). In rat vascular smooth muscle cells, leptin has been shown to induce hypertrophy through the activation of the p38 MAPK pathway (31).

Thus, there seems to be a link between leptin and diabetesinduced phathophysiological processes. Leptin has been shown to regulate the diabetes-induced increase in extracellular matrix (ECM) protein production in renal mesangial cells (34). Leptin is also involved in the increased production of fibronectin (FN) induced by diabetes and in cardiomyocyte hypertrophy (22). However, evidence that the leptin-induced activation of the $\mathrm{p} 38$ MAPK pathway may be involved in hyperglycemia-induced cardiomyocyte injury, including cytotoxicity, apoptosis, generation of reactive oxygen species (ROS) and the dissipation of mitochondrial membrane potential (MMP), is lacking. Thus, the aim purpose of the present study was to determine whether the leptin-induced activation of the p38 MAPK pathway contributes to hyperglycemia-induced cardiomyocyte injury. We also aimed to determine whether the inhibition of the leptin-induced activation of the-p38 MAPK pathway is involved in the protective effects of naringin against HG-induced injury in $\mathrm{H} 9 \mathrm{c} 2$ cardiac cells.

\section{Materials and methods}

Materials. Naringin with a purity of $\geq 98 \%$, was obtained from Sigma-Aldrich, St. Louis, MO, USA, stored at $2-4^{\circ} \mathrm{C}$ and protected from sunlight. Dichlorofluorescein diacetate (DCFH-DH), rhodamine (Rh123) and Hoechst 33258 were also purchased from Sigma-Aldrich. Leptin antagonist (LA) was supplied by Prospec (East Brunswick, NJ, USA). The Cell Counting kit-8 (CCK-8) was purchased from Dojindo Laboratories (Kumamoto, Japan). Fetal bovine serum (FBS) and DMEM-F12 medium were obtained from Gibco-BRL (Grand Island, NY, USA). Anti-p38 MAPK, anti-phosphop38 MAPK, anti-leptin and anti-leptin receptor antibodies were procured from Cell Signaling Technology (Boston, MA, USA). HRP-conjugated secondary antibody and the BCA protein assay kit were obtained from KangChen Bio-tech, Inc. (Shanghai, China). Enhanced chemiluminescence (ECL) solution was purchased from Nanjing KeyGen Biotech Co., Ltd. (Nanjing, China).

Cell culture and treatments. $\mathrm{H} 9 \mathrm{c} 2$ cardiac cells, a rat cardiomyoblast cell line, were supplied by the Sun Yat-sen University Experimental Animal Center (Guangzhou, China). The cells were grown in DMEM-F12 medium supplemented with $10 \%$ FBS under an atmosphere of $5 \% \mathrm{CO}_{2}$ at $37^{\circ} \mathrm{C}$ and $95 \%$ air.

The H9c2 cells were preconditioned with $80 \mu \mathrm{mol} / 1$ naringin for $2 \mathrm{~h}$ prior to exposure to $35 \mathrm{mmol} / \mathrm{l}$ glucose (HG) for $24 \mathrm{~h}$. To further determine whether the protective effects of naringin and the activation of the p38 MAPK pathway induced by $\mathrm{HG}$ are associated with leptin, the H9c2 cells were preconditioned with $50 \mathrm{ng} / \mathrm{ml} \mathrm{LA}$ for $24 \mathrm{~h}$ prior to exposure to $35 \mathrm{mmol} / \mathrm{l}$ glucose for $24 \mathrm{~h}$.

Measurement of cell viability. The $\mathrm{H} 9 \mathrm{c} 2$ cells were seeded in 96-well plates at a concentration of $1 \times 10^{4} \mathrm{cells} / \mathrm{ml}$, and incubated at $37^{\circ} \mathrm{C}$. The CCK- 8 assay was employed to assess the viability of the $\mathrm{H} 9 \mathrm{c} 2$ cardiac cells. After the indicated treat- ments, $10 \mu \mathrm{l}$ of CCK-8 solution were added to each well at a $1 / 10$ dilution and then the plate was incubated for $1.5 \mathrm{~h}$ in an incubator. With the use of a microplate reader (Molecular Devices, Sunnyvale, CA, USA) absorbance was assayed at $450 \mathrm{~nm}$. The mean optical density (OD) of 3 wells in the indicated groups was used to calculate the percentage of cell viability according to the following formula: cell viability $(\%)=\left(\mathrm{OD}_{\text {treatment group }} /\right.$ $\left.\mathrm{OD}_{\text {control group }}\right) \times 100 \%$. The experiment was repeated 5 times.

Hoechst 33258 nuclear staining for the detection of apoptosis. Apoptotic cell death was observed by Hoechst 33258 staining followed by photofluorography. In brief, the H9c2 cells were plated in $35 \mathrm{~mm}$ dishes at a density of $1 \times 10^{6}$ cells/well. After the indicated treatments, the $\mathrm{H} 9 \mathrm{c} 2$ cells were fixed with $4 \%$ paraformaldehyde in $0.1 \mathrm{~mol} / 1$ phosphate-buffered saline (PBS, $\mathrm{pH}$ 7.4) for $10 \mathrm{~min}$. The slides were then washed 5 times with PBS. After staining with $5 \mathrm{mg} / \mathrm{ml}$ Hoechst 33258 for $5 \mathrm{~min}$, the $\mathrm{H} 9 \mathrm{c} 2$ cells were washed 5 times with PBS and then visualized under a fluorescence microscope (Bx50-FLA; Olympus, Tokyo, Japan). Viable H9c2 cells displayed a uniform blue fluorescence throughout the nucleus and normal nuclear size. However, apoptotic H9c2 cells showed condensed, distorted or fragmented nuclei. The experiment was carried out 3 times.

Measurement of intracellular ROS generation. The generation of intracellular ROS was determined by the oxidative conversion of the cell-permeable oxidation of DCFH-DA into fluorescent DCF. The H9c2 cells were cultured on a slide with DMEM-F12 medium. After the different treatments, the slides were washed twice with PBS. DCFH-DA (10 $\mu \mathrm{mol} / \mathrm{l})$ solution in serum-free medium was then added to the slides, and the $\mathrm{H} 9 \mathrm{c} 2$ cells were then incubated in an incubator at $37^{\circ} \mathrm{C}$ for a further $30 \mathrm{~min}$. The slides were washed 5 times with PBS, and DCF fluorescence was measured over the entire field of vision with the use of a fluorescence microscope connected to an imaging system (BX50-FLA; Olympus). The mean fluorescence intensity (MFI) from 5 random fields was measured with the use of Image J 1.47i software and the MFI was used as an index of the amount of ROS. The experiment was carried out 5 times.

Measurement of MMP. MMP was assessed using a fluorescent dye, Rh123, a cell-permeable carionic dye that preferentially enters the mitochondria based on the highly negative MMP. The depolarization of MMP results in a decrease in green fluorescence. The H9c2 cells were cultured on a slide with DMEM-F12. After the indicated treatments, the slides were washed 3 times with PBS. The cells were incubated with $1 \mathrm{mg} / \mathrm{l} \mathrm{Rh} 123$ at $37^{\circ} \mathrm{C}$ for $30 \mathrm{~min}$ in an incubator and briefly washed 3 times with PBS and air dried. Fluorescence was then measured over the whole field of vision with the use of a fluorescence microscope connected to an imaging system (BX50-FLA; Olympus). The MFI of Rh123 from 5 random fields was analyzed using Image J 1.47 i software The MFI was taken as an index of the MMP levels. The experiment was carried out 5 times.

Western blot analysis. After the indicated treatments, the $\mathrm{H} 9 \mathrm{c} 2$ cells were harvested and lysed with cell lysis solution at $4^{\circ} \mathrm{C}$ for $30 \mathrm{~min}$. Total protein was quantified using the 
BCA protein assay kit. Loading buffer was added to the cytosolic extracts, and boiled for $5 \mathrm{~min}$; the same amounts of supernatant from each sample were subjected to $10 \%$ sodium dodecyl sulphate-polyacrylamide gel electrophoresis (SDS-PAGE), and then the total number of proteins was transferred onto polyvinylidene difluoride (PVDF) membranes. The membranes were blocked for $60 \mathrm{~min}$ in $5 \%$ fat-free milk in fresh blocking buffer $[0.1 \%$ Tween-20 in Tris-buffered saline (TBS-T)] at room temperature, and incubated with either anti-p38 (1:1,000 dilution), anti-phosphorylated (p)-p38 (1:1,000 dilution), anti-leptin (1:1,000 dilution) or anti-leptin receptor (1:1,000 dilution) antibodies in freshly prepared TBS-T with $3 \%$ fat-free milk overnight with gentle agitation at $4^{\circ} \mathrm{C}$. The membranes were washed for $15 \mathrm{~min}$ with TBS-T and incubated with horseradish peroxidase (HRP)conjugated goat anti-rabbit secondary antibody $(1: 2,500$ dilution; KangChen Biotech, Inc.) in TBS-T with 3\% fat-free milk for $1.5 \mathrm{~h}$ at room temperature. The membranes were then washed 3 times with TBS-T for $15 \mathrm{~min}$. The immunoreactive signals were visualized by using an ECL detection. In order to quantify the protein expression levels, the X-ray films were scanned and analyzed using ImageJ $1.47 \mathrm{i}$ software. The experiment was carried out 3 times.

Statistical analysis. All data are presented as the means \pm SEM. Differences between groups were analyzed by one-way analysis of variance (ANOVA) followed by the LSD post hoc comparison test. Statistical analyses were performed using SPSS 13.0 statistical software (SPSS, Chicago, IL, USA). Values of $\mathrm{P}<0.05$ were considered to indicate statistically significant differences.

\section{Results}

Naringin and LA attenuate the HG-induced increase in leptin expression levels in $\mathrm{H} 9 \mathrm{c} 2$ cardiac cells. In order to determine the effects of HG ( $35 \mathrm{mmol} / \mathrm{l}$ glucose) on leptin expression levels in $\mathrm{H} 9 \mathrm{c} 2$ cardiac cells, a time-response experiment on leptin expression levels was performed. Following exposure of the H9c2 cardiac cells to $35 \mathrm{mmol} / 1$ glucose for $3,6,9$, 12 and $24 \mathrm{~h}$, the leptin expression levels began to markedly increase at $6 \mathrm{~h}$, reaching a peak at $9 \mathrm{~h}$ (Fig. 1A and B). Thus, leptin expression levels were examined $9 \mathrm{~h}$ post-exposure to HG in the following experiments. Notably, prior to exposure to $35 \mathrm{mmol} / \mathrm{l}$ glucose, the H9c2 cells were treated with $80 \mu \mathrm{mol} / 1$ naringin for $2 \mathrm{~h}$. This pre-treatment significantly reduced the expression levels of leptin which were increased by $\mathrm{HG}$ (Fig. $1 \mathrm{C}$ and D).

In addition, the administration of $50 \mathrm{ng} / \mathrm{ml} \mathrm{LA}$ for $24 \mathrm{~h}$ prior to exposure to $\mathrm{HG}$, led to marked decrease in leptin expression levels (Fig. 1C and D). The basal expression levels of leptin (control) were not altered by the separate treatment with $80 \mu \mathrm{mol} / 1$ naringin or $50 \mathrm{ng} / \mathrm{ml} \mathrm{LA} \mathrm{(Fig.} \mathrm{1C} \mathrm{and} \mathrm{D).}$

Naringin attenuates the HG-induced increase in the expression levels of leptin receptors in $\mathrm{H} 9 \mathrm{c} 2$ cardiac cells. Western blot analysis (Fig. 2A and B) revealed that the exposure of $\mathrm{H} 9 \mathrm{c} 2$ cells to $35 \mathrm{mmol} / \mathrm{l}$ glucose for $1,3,6,9,12$ and $24 \mathrm{~h}$ induced the overexpression of leptin receptor $(\mathrm{Ob}-\mathrm{R})$ protein, peaking at $12 \mathrm{~h}$. The expression levels of $\mathrm{Ob}-\mathrm{R}$ began to decrease at
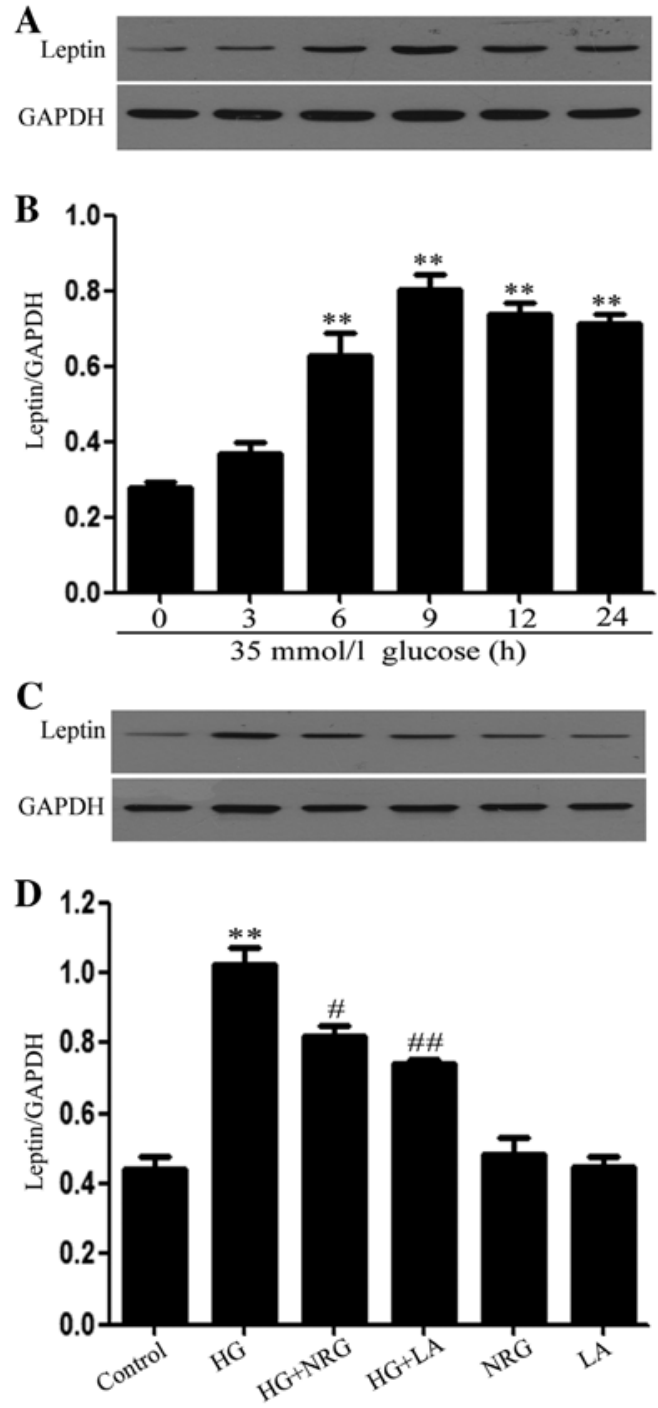

Figure 1. Naringin (NRG) and leptin antagonist (LA) suppress the high glucose (HG)-induced upregulation in leptin expression levels in H9c2 cardiac cells. (A and C) Leptin expression levels were semiquantified by western blot analysis. (A and B) Time course of changes observed in leptin expression levels induced by HG (35 mmol/1 glucose) over a 24 -h time period. (C and D) H9c2 cardiac cells were exposed to HG for $9 \mathrm{~h}$ with or without treatment with $80 \mu \mathrm{mol} / 1 \mathrm{NRG}$ for $2 \mathrm{~h}$ or with $50 \mathrm{ng} / \mathrm{ml} \mathrm{LA}$ for $24 \mathrm{~h}$ prior to exposure to HG. (B and D) Densitometric analysis of the leptin expression levels in (A and C). Data are presented as the means $\pm S E,(n=3) .{ }^{* *} \mathrm{p}<0.01$ vs. the control group; ${ }^{\#} \mathrm{p}<0.05,{ }^{\# \#} \mathrm{p}<0.01$ vs. the HG-treated group.

$24 \mathrm{~h}$, but remained much higher than those observed at $9 \mathrm{~h}$ (Fig. 2A and B).

Additionally, treatment with $80 \mu \mathrm{mol} / 1$ naringin for $2 \mathrm{~h}$ prior to exposure to $\mathrm{HG}$ markedly alleviated the increased $\mathrm{Ob}-\mathrm{R}$ expression levels detected $12 \mathrm{~h}$ after exposure to $\mathrm{HG}$ ( $\mathrm{p}<0.01)$ compared with the HG-treated group (Fig. 2C and D). Naringin alone, at $80 \mu \mathrm{mol} / 1$, did not alter the basal expression levels of leptin receptors in $\mathrm{H} 9 \mathrm{c} 2$ cells.

LA modulates the activation of $p 38 \mathrm{MAPK}$ induced by $H G$ in $H 9 c 2$ cardiac cells. Western blot analysis revealed that exposure of the H9c2 cells to HG markedly upregulated the expression levels of p-p38 MAPK (Fig. 3). The increased p-p38 MAPK expression levels were markedly suppressed by treatment with LA $(50 \mathrm{ng} / \mathrm{ml})$ for $24 \mathrm{~h}$ prior to exposure to 

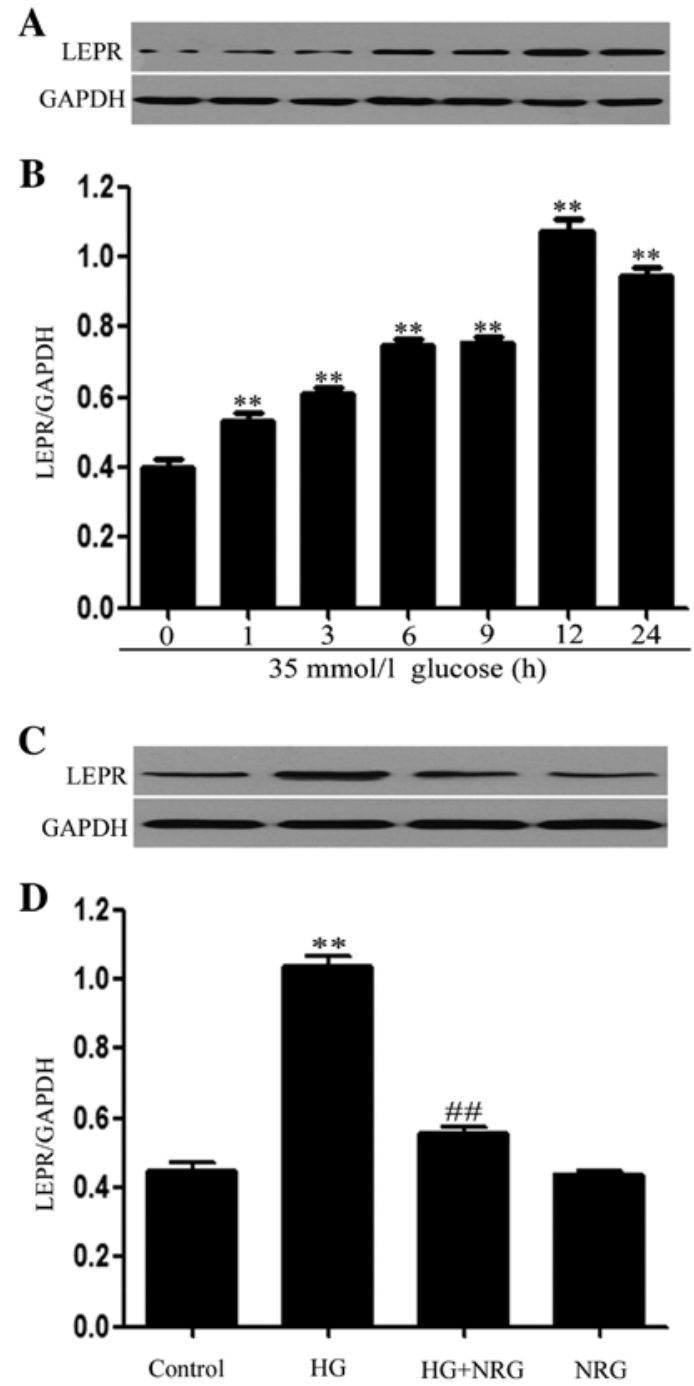

Figure 2. Naringin (NRG) attenuates the increase in the expression levels of leptin receptors induced by high glucose (HG) in $\mathrm{H} 9 \mathrm{c} 2$ cardiac cells. (A and C) Leptin receptor expression levels were measured by western blot analysis. (A and B) Time course of changes observed in leptin receptor expression levels induced by $\mathrm{HG}(35 \mathrm{mmol} / 1$ glucose) over a 24 -h time period. (C and D) H9c2 cardiac cells were exposed to HG for $12 \mathrm{~h}$ with or without treatment with $80 \mu \mathrm{mol} / \mathrm{l} \mathrm{NRG}$ for $2 \mathrm{~h}$ prior to exposure to HG. (B and D) Densitometric analysis of the leptin expression levels in (A and C). Data are presented as the means $\pm \mathrm{SE},(\mathrm{n}=3) .{ }^{*} \mathrm{p}<0.01$ vs. the control group;

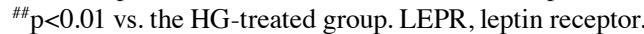

HG, indicating the involvement of leptin in the HG-induced activation of $\mathrm{p} 38$ MAPK in $\mathrm{H} 9 \mathrm{c} 2$ cardiac cells.

Naringin and LA alleviate HG-induced cytotoxicity in $H 9 c 2$ cardiac cells. Exposure of the H9c2 cells to HG for $24 \mathrm{~h}$ induced marked cytotoxic effects, leading to reduced cell viability (Fig. 4). However, the decreased cell viability was attenuated by treatment with $80 \mu \mathrm{mol} / 1$ naringin for $2 \mathrm{~h}$ or by treatment with $50 \mathrm{ng} / \mathrm{ml} \mathrm{LA}$ for $24 \mathrm{~h}$ prior to exposure to HG. cell viability levels still remained reduced compaired to the control group. Naringin or LA alone did not affect the viability of the H9c2 cardiac cells.

Naringin and LA attenuate $H G$-induced apoptosis in $H 9 c 2$ cardiac cells. As illustrated in Fig. 5B, exposure of the $\mathrm{H} 9 \mathrm{c} 2$ cells to $\mathrm{HG}$ for $24 \mathrm{~h}$ induced typical characteristics of
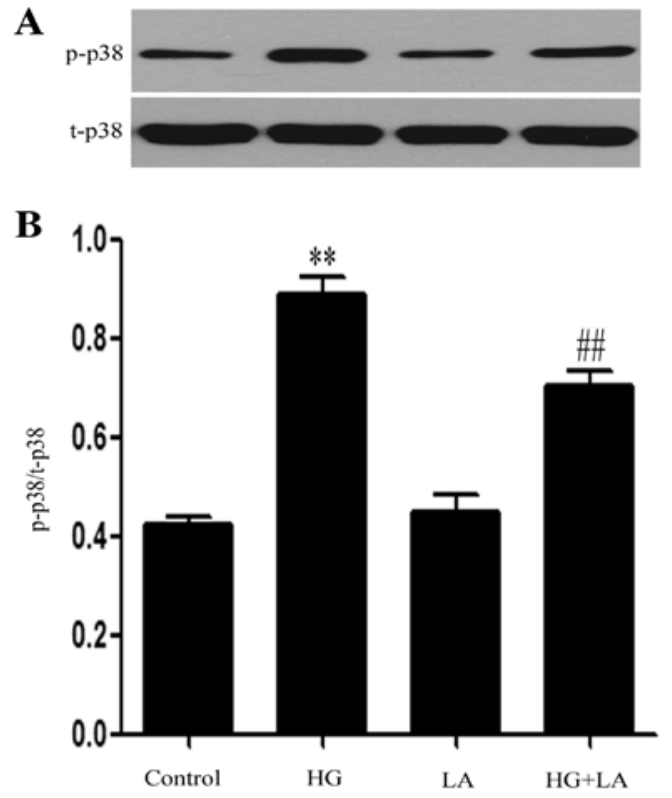

Figure 3. Leptin antagonist (LA) modulates the activation of mitogen-activated protein kinase (MAPK) induced by high glucose (HG) in $\mathrm{H} 9 \mathrm{c} 2$ cardiac cells. $\mathrm{H} 9 \mathrm{c} 2$ cells were preconditioned with $50 \mathrm{ng} / \mathrm{ml} \mathrm{LA}$ for $24 \mathrm{~h}$ prior to exposure of the cells to HG for $30 \mathrm{~min}$. (A) The expression levels of p38 MAPK were semiquantified by western blot analysis. (B) Densitometric analysis of the data (p-p38 MAPK) shown in (A). Data are presented as the means \pm SE, $(n=3)$. ${ }^{* *} \mathrm{p}<0.01$ vs. the control group; ${ }^{\# \#} \mathrm{p}<0.01$ vs. the HG-treated group. $\mathrm{p}-\mathrm{p} 38$ phosphorylated p38 MAPK; t-p38, total p38 MAPK.

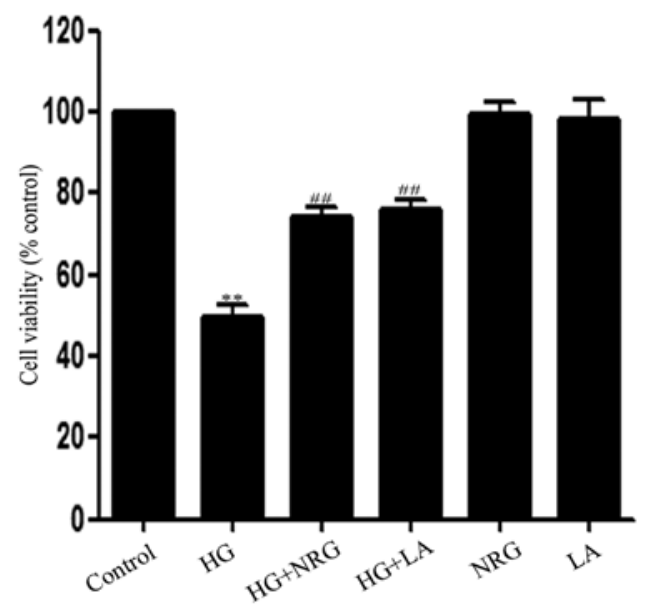

Figure 4. Naringin (NRG) and leptin antagonist (LA) alleviate high glucose (HG)-induced cytotoxicity in H9c2 cardiac cells. H9c2 cells were preconditioned with $80 \mu \mathrm{mol} / 1 \mathrm{NRG}$ for $2 \mathrm{~h}$ or with $50 \mathrm{ng} / \mathrm{ml} \mathrm{LA}$ for $24 \mathrm{~h}$ prior to exposure to HG. Cell viability was measured by CCK- 8 assay. Data are presented as the means $\pm \mathrm{SE},(\mathrm{n}=5)$. ${ }^{* *} \mathrm{p}<0.01 \mathrm{vs}$. the control group; ${ }^{\# \#} \mathrm{p}<0.01$ vs. the HG-treated group.

apoptosis, as indicated by the condensation of chromatin, the shrinkage of nuclei and the formation of apoptotic bodies. However, treatment of the cells with $80 \mu \mathrm{mol} / 1$ naringin for $2 \mathrm{~h}$ prior to exposure to $\mathrm{HG}$ markedly ameliorated the increase in the number of cells which presented nuclear condensation and fragmentation (Fig. 5C). In addition, treatment of the cells with $50 \mathrm{ng} / \mathrm{ml} \mathrm{LA}$ for $24 \mathrm{~h}$ prior to exposure to $\mathrm{HG}$ also alleviated HG-induced apoptosis (Fig. 5D). Naringin or LA alone did not significantly alter the morphology or the percentage 

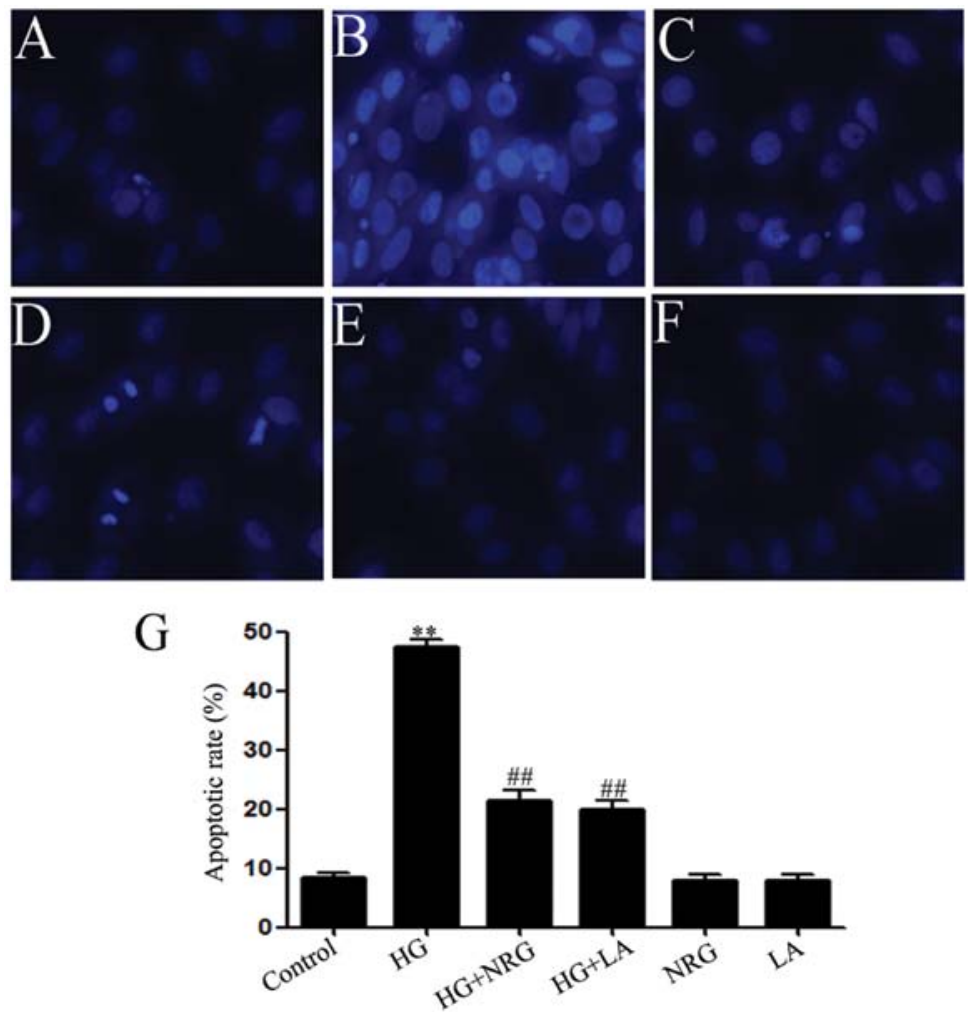

Figure 5. Naringin (NRG) and leptin antagonist (LA) reduce high glucose (HG)-induced apoptosis in H9c2 cardiac cells. (A-F) Hoechst 33258 nuclear staining followed by photofluorography was carried out to observe cell apoptosis. (A) Control group. (B) H9c2 cells exposed to 35 mmol/l glucose (HG) for 24 h. (C) H9c2 cells treated with $80 \mu \mathrm{mol} / 1 \mathrm{NRG}$ for $2 \mathrm{~h}$ prior to exposure to $\mathrm{HG}$ for $24 \mathrm{~h}$. (D) H9c2 cells treated with $50 \mathrm{ng} / \mathrm{ml} \mathrm{LA}$ for $24 \mathrm{~h}$ prior to exposure to HG for $24 \mathrm{~h}$. (E) H9c2 cells trreated with $80 \mu \mathrm{mol} / 1 \mathrm{NRG}$ for $2 \mathrm{~h}$. (F) H9c2 cells treated with $50 \mathrm{ng} / \mathrm{ml}$ LA for $24 \mathrm{~h}$. (G) The apoptotic rate was analyzed using a cell counter and Image J $1.47 \mathrm{i}$ software. Data are presented as the means $\pm \mathrm{SE},(\mathrm{n}=3) .{ }^{* *} \mathrm{p}<0.01$ vs. the control group; ${ }^{\# \#} \mathrm{p}<0.01$ vs. the HG-treated group.

of apoptotic H9c2 cells (Fig. 5E-G). These findings suggest that naringin protects the $\mathrm{H} 9 \mathrm{c} 2$ cells against $\mathrm{HG}$-induced apoptosis, which is related at least in part, with the increase in leptin expression.

Naringin and LA alleviate the HG-induced increase in ROS generation in $H 9 c 2$ cells. Previous studies have demonstrated that ROS generation is involved in HG-induced cardiomyocyte injury $(35,36)$. Thus, in this study, we explored the effects of naringin on HG-induced ROS generation in $\mathrm{H} 9 \mathrm{c} 2$ cells. The exposure of the H9c2 cells to HG for 24 h markedly enhanced ROS generation (Fig. 6B and G). The increase in ROS generation was suppressed by treatment of the cells with $80 \mu \mathrm{mol} / 1$ naringin for $2 \mathrm{~h}$ prior to exposure to HG (Fig. 6C and $\mathrm{G})$, revealing the inhibitory effects of naringin on HG-induced oxidative stress. In order to determine whether leptin is involved in the HG-induced overproduction of ROS, the H9c2 cells were treated with $50 \mathrm{ng} / \mathrm{ml} \mathrm{LA}$ for $24 \mathrm{~h}$ prior to exposure to HG. Our results revealed that treatment with LA considerably diminished the $\mathrm{HG}$-induced increase in ROS generation (Fig. 6D and G), indicating the involvement of leptin in HG-induced ROS overproduction.

Naringin and LA block the HG-induced dissipation of MMP in $H 9 c 2$ cells. Since mitochondrial damage has been shown to contribute to HG-induced cardiomyocyte injury $(37,38)$, we investigated whether naringin can prevent the loss of MMP in HG-treated H9c2 cells. Our results revealed that the exposure of the cells to $\mathrm{HG}$ for $24 \mathrm{~h}$ induced mitochondrial damage, as indicated by the dissipation of MMP (Fig. 7B and G). Of note, the dissipation of MMP was attenuated by treatment of the cells with $80 \mu \mathrm{mol} / 1$ naringin for $2 \mathrm{~h}$ prior to exposure to $\mathrm{HG}$ (Fig. 7C and G), indicating that naringin protected the $\mathrm{H} 9 \mathrm{c} 2$ cells against HG-induced mitochondrial damage. Similarly, treatment of the cells with $50 \mathrm{ng} / \mathrm{ml} \mathrm{LA}$ for $24 \mathrm{~h}$ prior to exposure to $\mathrm{HG}$, attenuated the $\mathrm{HG}$-induced dissipation of MMP, suggesting the involvement of leptin in the HG-induced dissipation of MMP (Fig. 7D and G).

\section{Discussion}

Hyperglycemia, an important feature of diabetes mellitus (DM), is considered to be the most important factor leading to almost all complications associated with chronic diabetes, including diabetic cardiomyopathy $(39,40)$. However, the mechanisms underlying the deteriorative effects of hyperglycemia on cardiomyocytes are not yet fully understood. A number of factors, such as ROS generation $(35,36)$ mitochondrial insult $(37,38)$ and the activation of MAPKs $(12,41-43)$, have been shown to participate in hyperglycemia-induced injury. Majumdar et al (22) reported that the exposure of neonatal rat cardiomyocytes to $25 \mathrm{mmol} / \mathrm{l}$ glucose induced increased mRNA and protein expression levels of both leptin and endothelin-1 (ET-1), which are involved in HG-induced cardiomyocyte hypertrophy. Consistent with these findings (22), our results demonstrated that the exposure of $\mathrm{H} 9 \mathrm{c} 2$ cardiac cells to $\mathrm{HG}$ ( $35 \mathrm{mmol} / \mathrm{l}$ glucose) 

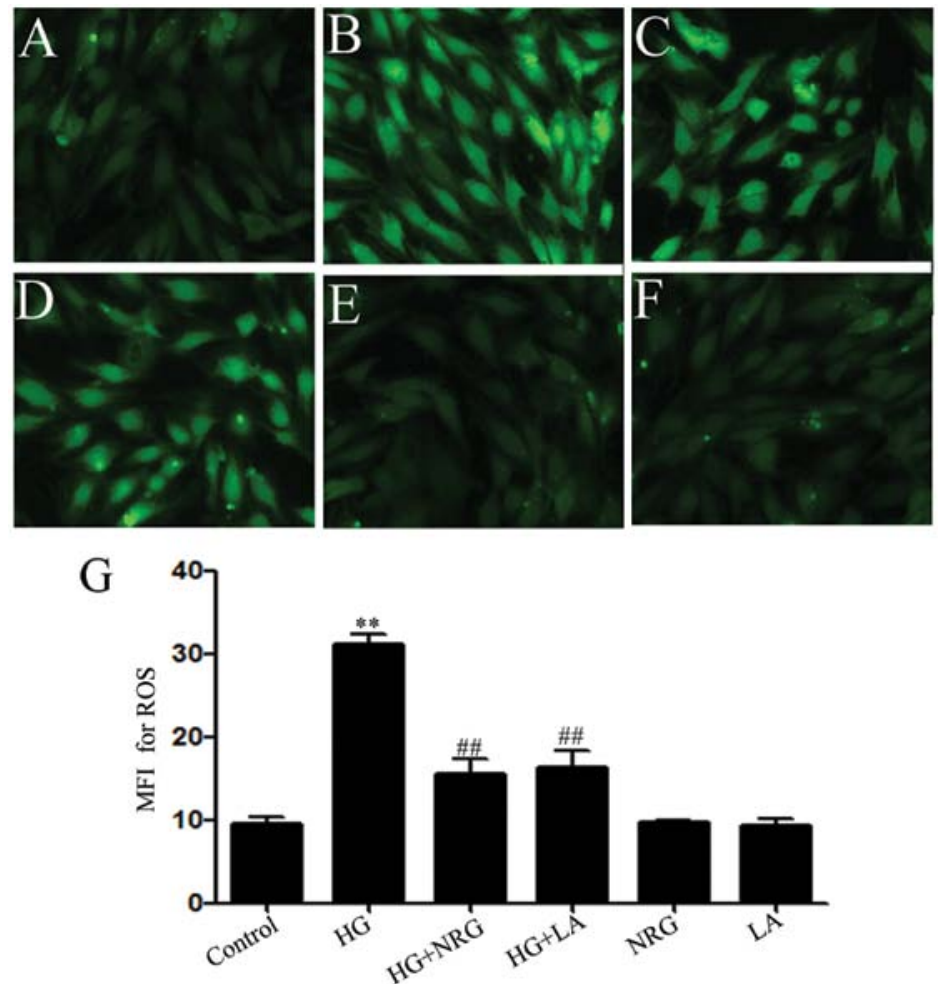

Figure 6. Naringin (NRG) and leptin antagonist (LA) reduce high glucose (HG)-induced ROS generation in H9c2 cells. (A-F) DCF staining followed by photofluorography was carried out in order to observe intracellular ROS levels. (A) Control group. (B) H9c2 cells exposed to $35 \mathrm{mmol} / 1 \mathrm{glucose}$ (HG) for $24 \mathrm{~h}$. (C) $\mathrm{H} 9 \mathrm{c} 2$ cells treated with $80 \mu \mathrm{mol} / 1 \mathrm{NRG}$ for $2 \mathrm{~h}$ prior to exposure to HG for $24 \mathrm{~h}$. (D) H9c2 cells treated with $50 \mathrm{ng} / \mathrm{ml} \mathrm{LA}$ for $24 \mathrm{~h}$ prior to exposure to HG for $24 \mathrm{~h}$. (E) H9c2 cells treated with $80 \mu \mathrm{mol} / 1 \mathrm{NRG}$ for $2 \mathrm{~h}$. (F) H9c2 cells treated with $50 \mathrm{ng} / \mathrm{ml} \mathrm{LA}$ for $24 \mathrm{~h}$. (G) Quantitative analysis of mean fluorescence intensity (MFI) was carried out using ImageJ 1.47i software in each group (A-F). Data are presented as the means \pm SE, $(n=3) .{ }^{* *} p<0.01$ vs. the control group; ${ }^{\# \#} \mathrm{p}<0.01$ vs. the HG-treated group.
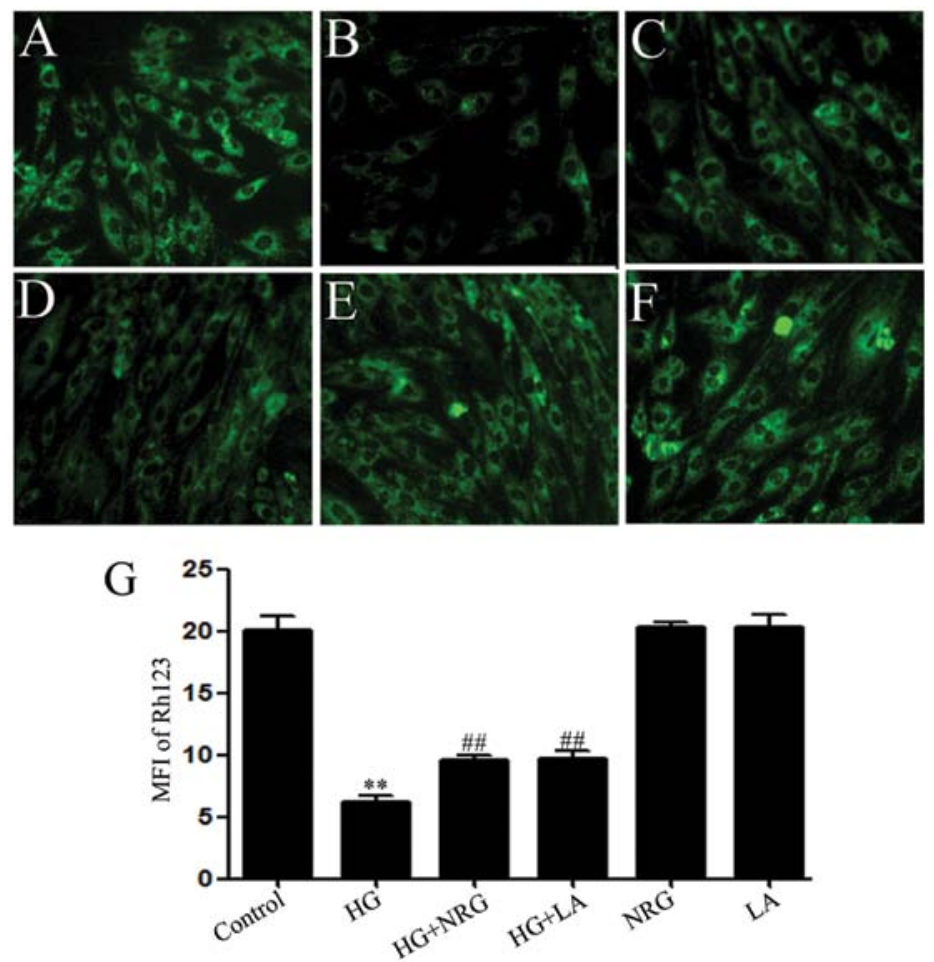

Figure 7. Naringin (NRG) and leptin antagonist (LA) block the high glucose (HG)-induced dissipation of mitochondrial membrane potential (MMP) in H9c2 cells. (A-F) After the indicated treatments, MMP was measured by Rh123 staining followed by photofluorography. (A) Control group. (B) H9c2 cells exposed to $35 \mathrm{mmol} / 1$ glucose (HG) for $24 \mathrm{~h}$. (C) $\mathrm{H} 9 \mathrm{c} 2$ cells treated with $80 \mu \mathrm{mol} / 1 \mathrm{NRG}$ for $2 \mathrm{~h}$ prior to exposure to $\mathrm{HG}$ for $24 \mathrm{~h}$. (D) $\mathrm{H} 9 \mathrm{c} 2 \mathrm{cells}$ treated with $50 \mathrm{ng} / \mathrm{ml} \mathrm{LA}$ for $24 \mathrm{~h}$ prior to exposure to HG for $24 \mathrm{~h}$. (E) H9c2 cells treated with $80 \mu \mathrm{mol} / 1 \mathrm{NRG}$ for $2 \mathrm{~h}$. (F) H9c2 cells treated with $50 \mathrm{ng} / \mathrm{ml} \mathrm{LA} \mathrm{for} 24 \mathrm{~h}$. (G) Quantitative analysis of the mean fluorescence intensity (MFI) of Rh123 in (A-G) was carried out using ImageJ 1.47i software. Data are presented as the means \pm SE, (n=3). ${ }^{* *} \mathrm{p}<0.01$ vs. the control group; ${ }^{\#} \mathrm{p}<0.01$ vs. the HG-treated group. 
markedly upregulated the expression levels of both leptin and leptin receptor. Since leptin has been shown to participate in HG-induced cardiomyocyte hypertrophy (22), we investigated whether leptin conributes to other injuries induced by HG. The findings of this study demonstrated that the exposure of the cells to HG induced marked changes, as shown by the decrease in cell viability, the increase in the apoptotic cell number and ROS generation, as well as in the dissipation of MMP. However, these injuries induced by HG were significantly attenuated by treatment with LA prior to exposure to $\mathrm{HG}$, suggesting that leptin is involved in HG-induced cytotoxicity, apoptosis, ROS generation and mitochondrial damage. Our data confirm the data from a previous study (22), and provide novel evidence of the role of leptin in hyperglycemia-induced cardiomyocyte injury.

Additionally, we observed that the exposure of the cells to $\mathrm{HG}$, induced an increase in p-p38 MAPK expression levels, which is in accordance with the findings of previous studies (12,41-43). Importantly, the high expression levels of p-p38 MAPK were decreased by treatment with LA prior to exposure to $\mathrm{HG}$, indicating that leptin acts upstream of p38 MAPK and contributes to the HG-induced activation of the p38 MAPK pathway in H9c2 cells. It is known that p38 MAPK is activated by a diverse range of physical and chemical stresses, such as hypoxia/ischemia $(44,45)$, drugs $(46,47)$ and oxidative stress (48). To the best of our knowledge, only a few studies to date have addressed the role of p38 MAPK in leptin signaling in different cell types $(30-33,49)$; for example, leptin has been shown to induce hypertrophy through he activation of p38 MAPK in rat vascular smooth muscle cells (31). However, it remains unclear as to whether the leptin-induced activation of the p38 MAPK pathway is involved in HG-induced cardiomyocyte injury. Recently, we (12), as well as others [Xu et al (42)] demonstrated the contribution of p38 MAPK activation to HG-induced injury in $\mathrm{H} 9 \mathrm{c} 2$ cardiac cells. Thus, the data from the current study (Figs. 3-7), as well as those from previous studies $(12,42)$, provide evidence that the leptin-induced activation of the p38 MAPK pathway may be an important mechanism responsible for HG-induced injury in $\mathrm{H} 9 \mathrm{c} 2$ cardiac cells.

Naringin, a citrus flavonone, has been shown to exert protective effects against hyperglycemia-induced cardiac injury in DM and has attracted considerable attention due to its broad spectrum of pharmacological and therapeutic properties (1-16), including its antihyperglycemic $(13,14)$, anti-apoptotic $(9-12)$ and cardioprotective $(12,15,16)$ effects. In a recent study, we demonstrated that naringin protects cardiomyocytes against HG-induced injury by modulating the activation of the p38 MAPK pathway (12). However, the mechanisms underlying the cardioprotective effects of naringin, including the effects of naringin on the leptin-induced activation of the p38 MAPK pathway remain unclear. Thus, in the present study, we explored the effects of naringin on the leptin-induced activation of the p38 MAPK pathway in H9c2 cardiac cells exposed to HG. Our results demonstrated that naringin markedly attenuated the HG-induced increase in the expression levels of both leptin and leptin receptors, indicating the inhibitory effects of naringin on the increase in leptin expression induced by HG. Since we have previously demonstrated that naringin inhibits the HG-induced activation of the p38 MAPK pathway (12), the findings of the current study support the notion that naringin protects $\mathrm{H} 9 \mathrm{c} 2$ cardiac cells against HG-induced injury, at least in part through the inhibition of the leptin-induced activation of the p38 MAPK pathway. This is clearly supported by the following evidence: i) the inhibitory effects of naringin on the increased expression of both leptin and leptin receptor induced by HG; ii) the inhibitory effects of LA on the HG-induced activation of p38 MAPK; iii) the inhibitory effects of naringin on the HG-induced activation of p38 MAPK (12); iv) the protective effects of both naringin and LA against HG-induced cardiomyocyte injury, leading to an increase in cell viability, as well as a decrease in the number of apoptotic cells, ROS generation, and in the attenuation of the loss of MMP; v) the inhibitory effects of SB203580, an inhibitor of p38 MAPK, on HG-induced injury $(12,42)$.

In conclusion, this study provides the first evidence that the leptin-induced activation of the p38 MAPK pathway contributes to HG-induced cardiomyocyte injury, including cytotoxicity, apoptosis, oxidative stress and mitochondrial damage. The understanding of the role of such a pathway is important, as it may lead to the development of novel treatment strategies for diabetic cardiomyopathy. In addition, we provide novel evidence that the inhibition of the leptin-induced activation of the p38 MAPK pathway is involved in the cardioprotective effects of naringin against hyperglycemia-induced cardiomyocyte injury. These findings provider a deeper understanding of the mechanisms responsible for the cytoprotective effects of naringin against cardiovascular complications associated with diabetes and its pharmacological and therapeutic properties.

\section{Acknowledgements}

This study was supported by grants from the Science and Technology Planning Project of Guangdong in China (no. 2012A080202020) and the Guangdong Natural Science Foundation (no. S2011010002620).

\section{References}

1. Mahmoud AM, Ashour MB, Abdel-Moneim A and Ahmed OM: Hesperidin and naringin attenuate hyperglycemia-mediated oxidative stress and proinflammatory cytokine production in high fat fed/streptozotocin-induced type 2 diabetic rats. J Diabetes Complications 26: 483-490, 2012.

2. Rajadurai $M$ and Prince PS: Preventive effect of naringin on isoproterenol-induced cardiotoxicity in Wistar rats: an in vivo and in vitro study. Toxicology 232: 216-225, 2007.

3. Jeon SM, Park YB and Choi MS: Antihypercholesterolemic property of naringin alters plasma and tissue lipids, cholesterolregulating enzymes, fecal sterol and tissue morphology in rabbits. Clin Nutr 23: 1025-1034, 2004.

4. Jain M and Parmar HS: Evaluation of antioxidative and antiinflammatory potential of hesperidin and naringin on the rat air pouch model of inflammation. Inflamm Res 60: 483-491, 2011.

5. Bodas R, Prieto N, López-Campos O, Giráldez FJ and Andrés S: Naringin and vitamin E influence the oxidative stability and lipid profile of plasma in lambs fed fish oil. Res Vet Sci 91: 98-102, 2011.

6. Jung UJ, Kim HJ, Lee JS, et al: Naringin supplementation lowers plasma lipids and enhances erythrocyte antioxidant enzyme activities in hypercholesterolemic subjects. Clin Nutr 22: 561-568, 2003.

7. Kim HJ, Oh GT, Park YB, Lee MK, Seo HJ and Choi MS: Naringin alters the cholesterol biosynthesis and antioxidant enzyme activities in LDL receptor-knockout mice under cholesterol fed condition. Life Sci 74: 1621-1634, 2004. 
8. Nie YC, Wu H, Li PB, et al: Anti-inflammatory effects of naringin in chronic pulmonary neutrophilic inflammation in cigarette smoke-exposed rats. J Med Food 15: 894-900, 2012.

9. Jagetia GC, Venkatesha VA and Reddy TK: Naringin, a citrus flavonone, protects against radiation-induced chromosome damage in mouse bone marrow. Mutagenesis 18: 337-343, 2003.

10. Kanno S, Shouji A, Asou K and Ishikawa M: Effects of naringin on hydrogen peroxide-induced cytotoxicity and apoptosis in P388 cells. J Pharmacol Sci 92: 166-170, 2003.

11. Kanno S, Shouji A, Hirata R, Asou K and Ishikawa M: Effects of naringin on cytosine arabinoside (Ara-C)-induced cytotoxicity and apoptosis in P388 cells. Life Sci 75: 353-365, 2004.

12. Huang H, Wu K, You Q, Huang R, Li S and Wu K: Naringin inhibits high glucose-induced cardiomyocyte apoptosis by attenuating mitochondrial dysfunction and modulating the activation of the p38 signaling pathway. Int J Mol Med 32: 396-402, 2013.

13. Adel AM, Mohamed BA, Ayman MM and Osama MA: Insulin sensitizing effects of hesperidin and naringin in experimental kmodel of induced type 2 diabetes in rats: focus on tumor necrosis factor-alpha and resistin. Nat Sci 7: 134-141, 2011.

14. Osama MA, Ayman MM, Adel AM and Mohamed BA: Antihyperglycemic and antihyperlipidemic effects of hesperidin and naringin in high fat diet/streptozotocin type 2 diabetic rats. Life Sci J 8: 91-101, 2011.

15. Rajadurai $M$ and Prince PS: Preventive effect of naringin on cardiac mitochondrial enzymes during isoproterenol-induced myocardial infarction in rats: a transmission electron microscopic study. J Biochem Mol Toxicol 21: 354-361, 2007.

16. Rajadurai M and Prince PS: Naringin ameliorates mitochondrial lipid peroxides, antioxidants and lipids in isoproterenol-induced myocardial infarction in Wistar rats. Phytother Res 23: 358-362, 2009.

17. Tartaglia LA: The leptin receptor. J Biol Chem 272: 6093-6096, 1997.

18. Murad A, Nath AK, Cha ST, Demir E, Flores-Riveros J and Sierra-Honigmann MR: Leptin is an autocrine/paracrine regulator of wound healing. FASEB J 17: 1895-1897, 2003.

19. La Cava A, Alviggi C and Matarese G: Unraveling the multiple roles of leptin in inflammation and autoimmunity. J Mol Med (Berl) 82: 4-11, 2004.

20. Ren J: Leptin and hyperleptinemia - from friend to foe for cardiovascular function. J Endocrinol 181: 1-10, 2004

21. Figenschau Y, Knutsen G, Shahazeydi S, Johansen O and Sveinbjörnsson B: Human articular chondrocytes express functional leptin receptors. Biochem Biophys Res Commun 287: 190-197, 2001

22. Majumdar P, Chen S, George B, Sen S, Karmazyn M and Chakrabarti S: Leptin and endothelin-1 mediated increased extracellular matrix protein production and cardiomyocyte hypertrophy in diabetic heart disease. Diabetes Metab Res Rev 25: 452-463, 2009.

23. Wallace AM, McMahon AD, Packard CJ, et al: Plasma leptin and the risk of cardiovascular disease in the west of Scotland coronary prevention study (WOSCOPS). Circulation 104: 3052-3056, 2001.

24. Hoggard N, Mercer JG, Rayner DV, Moar K, Trayhurn P and Williams LM: Localization of leptin receptor mRNA splice variants in murine peripheral tissues by RT-PCR and in situ hybridization. Biochem Biophys Res Commun 232: 383-387, 1997.

25. Kieffer TJ, Heller RS and Habener JF: Leptin receptors expressed on pancreatic beta-cells. Biochem Biophys Res Commun 224: 522-537, 1996

26. Lin J, Barb CR, Matteri RL, Kraeling RR, Chen $X$ Meinersmann RJ and Rampacek GB: Long form leptin receptor mRNA expression in the brain, pituitary, and other tissues in the pig. Domest Anim Endocrinol 19: 53-61, 2000.

27. Bjørbaek C, Uotani S, da Silva B and Flier JS: Divergent signaling capacities of the long and short isoforms of the leptin receptor. J Biol Chem 272: 32686-32695, 1997.

28. Bjørbaek C, Buchholz RM, Davis SM, et al: Divergent roles of SHP-2 in ERK activation by leptin receptors. J Biol Chem 276: 4747-4755, 2001

29. Bouloumie A, Marumo T, Lafontan M and Busse R: Leptin induces oxidative stress in human endothelial cells. FASEB J 13 1231-1238, 1999.
30. van den Brink GR, O'Toole T,Hardwick JC, van den Boogaardt DE, Versteeg HH, van Deventer SJ and Peppelenbosch MP: Leptin signaling in human peripheral blood mononuclear cells, activation of p38 and p42/44 mitogen-activated protein (MAP) kinase and p70 S6 kinase. Mol Cell Biol Res Commun 4: 144-150, 2000

31. Shin HJ, Oh J, Kang SM, et al: Leptin induces hypertrophy via p38 mitogen-activated protein kinase in rat vascular smooth muscle cells. Biochem Biophys Res Commun 329: 18-24, 2005.

32. Rajapurohitam V, Gan XT, Kirshenbaum LA and Karmazyn M: The obesity-associated peptide leptin induces hypertrophy in neonatal rat ventricular myocytes. Circ Res 93: 277-279, 2003.

33. Zeidan A, Javadov S, Chakrabarti S and Karmazyn M: Leptininduced cardiomyocyte hypertrophy involves selective caveolae and RhoA/ROCK-dependent p38 MAPK translocation to nuclei. Cardiovasc Res 77: 64-72, 2008

34. Han DC, Isono M, Chen S, Casaretto A, Hong SW, Wolf G and Ziyadeh FN: Leptin stimulates type I collagen production in $\mathrm{db} / \mathrm{db}$ mesangial cells: glucose uptake and TGF-beta type II receptor expression. Kidney Int 59: 1315-1323, 2001.

35. Peake BF, Nicholson CK, Lambert JP, Hood RL, Amin H, Amin S and Calvert JW: Hydrogen sulfide preconditions the $\mathrm{db} / \mathrm{db}$ diabetic mouse heart against ischemia-reperfusion injury by activating Nrf2 signaling in an Erk-dependent manner. Am J Physio Heart Circ Physiol 304: H1215-H1224, 2013.

36. Ganesan K, Gani SB and Arunachalam GM: Effect of Helicteres isora bark extracts on heart antioxidant status and lipid peroxidation in streptozotocin diabetic rats. J Appl Biomed 6: 89-95, 2008 .

37. Boudina S, Sena S, Theobald H, et al: Mitochondrial energetics in the heart in obesity-related diabetes: direct evidence for increased uncoupled respiration and activation of uncoupling proteins. Diabetes 56: 2457-2466, 2007.

38. Ceriello A: Cardiovascular effects of acute hyperglycaemia: pathophysiological underpinnings. Diab Vasc Dis Res 5: 260-268, 2008

39. Brownlee M: Biochemistry and molecular cell biology of diabetic complications. Nature 414: 813-820, 2001.

40. Ren J and Davidoff AJ: Diabetes rapidly induces contractile dysfunctions in isolated ventricular myocytes. Am J Physiol 272: H148-H158, 1997.

41. Soetikno V, Sari FR, Sukumaran V, et al: Curcumin prevents diabetic cardiomyopathy in streptozotocin-induced diabetic rats: possible involvement of PKC-MAPK signaling pathway. Eur J Pharm Sci 47: 604-614, 2012.

42. Xu W, Wu W, Chen J, Guo R, Lin J, Liao X and Feng J: Exogenous hydrogen sulfide protects $\mathrm{H} 9 \mathrm{c} 2$ cardiac cells against high glucose-induced injury by inhibiting the activities of the p38 MAPK and ERK1/2 pathways. Int J Mol Med 32: 917-925, 2013.

43. Yan J, Young ME, Cui L, Lopaschuk GD, Liao R and Tian R: Increased glucose uptake and oxidation in mouse hearts prevent high fatty acid oxidation but cause cardiac dysfunction in dietinduced obesity. Circulation 119: 2818-2828, 2009.

44. Liu AL, Wang XW, Liu AH, Su XW, Jiang WJ, Qiu PX and Yan GM: JNK and p38 were involved in hypoxia and reoxygenation-induced apoptosis of cultured rat cerebellar granule neurons. Exp Toxicol Pathol 61: 137-143, 2009.

45. Lan A, Liao X, Mo L, et al: Hydrogen sulfide protects against chemical hypoxia-induced injury by inhibiting ROS-activated ERK1/2 and p38MAPK signaling pathways in PC12 cells. PLoS One 6: e25921, 2011

46. Guo R, Lin J, Xu W, Shen N, Mo L, Zhang C and Feng J: Hydrogen sulfide attenuates doxorubicin-induced cardiotoxicity by inhibition of the p38 MAPK pathway in H9c2 cells. Int J Mol Med 31: 644-650, 2013

47. Guo RM, Xu WM, Lin JC, et al: Activation of the p38 MAPK/ $\mathrm{NF}-\kappa \mathrm{B}$ pathway contributes to doxorubicin-induced inflammation and cytotoxicity in H9c2 cardiac cells. Mol Med Rep 8: 603-608, 2013.

48. Chen L, Liu L, Yin J, Luo Y and Huang S: Hydrogen peroxideinduced neuronal apoptosis is associated with inhibition of protein phosphatase $2 \mathrm{~A}$ and 5 , leading to activation of MAPK pathway. Int J Biochem Cell Biol 41: 1284-1295, 2009.

49. Tajmir P, Ceddia RB, Li RK, Coe IR and Sweeney G: Leptin increases cardiomyocyte hyperplasia via extracellular signalregulated kinase- and phosphatidylinositol 3-kinase-dependent signaling pathways. Endocrinology 145: 1550-1555, 2004. 